\title{
Risk and reward
}

T seemed to be good news when a company of worldwide fame

1 started marketing cutting-edge medical devices. But, it has become disastrous now that all of the people responsible for patient safety have overlooked their duties. This is the story of Articular Surface Replacement (ASR) from Johnson \& Johnson's DePuy Orthopaedics.

The ASR was, at first, a popular metal hip implant designed to solve the problems of previous models consisting of metal and plastic. An ASR has a cup component that would fit into a recipient's hip socket, and has an internal groove against which a doctor can locate a surgical appliance during the operation. This groove, in itself, restricted the device's ball movement inside the cup. Consequently, severe wearing with metal debris resulted from frequent collision between the edge of the cup and the body of the ball part. This phenomenon inevitably led to early failures of the ASR, and some practitioners reported their serious concerns to the company. The device showed a failure rate of approximately $40 \%$ within 5 years of implantation.

In the beginning, the DePuy hip implant did not achieve an acceptable wear rate in their internal test performed in the company's own lab. However, instead of reporting this issue to doctors and patients, DePuy intentionally changed the test until they obtained favorable results. To our disappointment, the company's interest was not patient safety but financial gain. It is also questionable whether the physicians, who then worked as 
consultants to that company, fulfilled their responsibility and sounded the public alarm as soon as they should have. Therefore, nearly 120,000 patients around the world received this defective biomedical device without correct information from the manufacturer and the consulting physicians. Although numerous lawsuits over this device are awaiting court decisions, the court of public opinion has already ruled this situation a case of amorality and nescience.

In this sad moment, the Scottish philosopher David Hume's writing can be appreciated. In A Treatise on Human Nature, he observed that we humans tend to search for a justification to do whatever we please: "All morality depends upon our sentiments; and when any action or quality of the mind pleases us after a certain manner we say it is virtuous; and when the neglect or nonperformance of it displeases us after a like manner, we say that we lie under an obligation to perform it."

Let this tragic case be a lesson to us. We already know it is only a matter of time before science without validation becomes harmful superstition. To maintain the standards of science and protect our patients, we must simply remain determined, even when it inconveniences us, to keep our virtue.

\section{Tae-II Kim}

Editor-in-Chief

Department of Periodontology, Seoul National University School of Dentistry,

101 Daehak-ro, Jongno-gu, Seoul 110-749, Korea

E-mail: periopf@snu.ac.kr, Tel: +82-2-2072-2642, Fax: +82-2-744-1349 